Article

\title{
Facile synthesis of Mesoporouscobalt Hexacyanoferrate Nanocubes for High-Performance Supercapacitors
}

\author{
Zhiyong Zhang ${ }^{1} \mathbb{C}^{(\mathbb{D}}$, Jian-Gan Wang ${ }^{1, *}$ (]) and Bingqing Wei ${ }^{1,2, *}$ \\ 1 State Key Laboratory of Solidification Processing, Center for Nano Energy Materials, School of Materials \\ Science and Engineering, Northwestern Polytechnical University and Shaanxi Joint Lab of Graphene (NPU), \\ Xi'an 710072, China; zyzhang@mail.nwpu.edu.cn \\ 2 Department of Mechanical Engineering, University of Delaware, Newark DE19716, USA \\ * Correspondence: wangjiangan@nwpu.edu.cn (J.-G.W.); weib@udel.edu (B.W.); \\ Tel.: +86-029-8846-0204 (J.-G.W. \& B.W.)
}

Received: 1 August 2017; Accepted: 18 August 2017; Published: 21 August 2017

\begin{abstract}
Mesoporous cobalt hexacyanoferrate nanocubes (meso-CoHCF) were prepared for the first time through a facile sacrificial template method. The CoHCF mesostructures possess a high specific surface area of $548.5 \mathrm{~m}^{2} \cdot \mathrm{g}^{-1}$ and a large amount of mesopores, which enable fast mass transport of electrolyte and abundant energy storage sites. When evaluated as supercapacitor materials, the meso-CoHCF materials exhibit a high specific capacitance of $285 \mathrm{~F} \cdot \mathrm{g}^{-1}$, good rate capability and long cycle life with capacitance retention of $92.9 \%$ after 3000 cycles in $\mathrm{Na}_{2} \mathrm{SO}_{4}$ aqueous electrolyte. The excellent electrochemical properties demonstrate the rational preparation of mesoporous prussian blue and its analogues for energy storage applications.
\end{abstract}

Keywords: prussian blue; electrode material; mesostructure; supercapacitor

\section{Introduction}

Supercapacitors, also known as electrochemical capacitors, are considered one of the most promising energy storage devices, owing to their desirable properties of high power density, high energy density and excellent cycling stability [1]. Based on the charge-storage mechanism, supercapacitors can be generally classified into two types: electrical double-layer capacitors (EDLCs) and pseudocapacitors. The former stores charges through electrostatic adsorption/desorption at the electrode-electrolyte interface; while the energy of pseudocapacitors comes from rapid Faradaic reactions occurred at the surface of electrode materials [2]. For EDLCs, carbonaceous materials with large surface area are widely used, such as activated carbon [3], carbon nanotubes [4], carbon xerogel [5] and graphene [6]. The most widely investigated electrode materials of pseudocapacitors include conducting polymers and transition-metal oxides or hydroxides [7,8].

As a representative of the metal organic framework materials, prussian blue (PB) can be generally expressed as $\mathrm{A}_{x} \mathrm{Fe}\left[\mathrm{Fe}(\mathrm{CN})_{6}\right]_{y} \cdot m \mathrm{H}_{2} \mathrm{O}(\mathrm{A}$, alkaline metal; $0<x<2, y<1)[9,10]$. In the framework of $\mathrm{PB}, \mathrm{Fe}$ in low-spin and high-spin state bond with six $\mathrm{C}$ and six $\mathrm{N}$ atoms, respectively, forming face-centered-cube (FCC) crystal structure and resultant open channels [11-13]. Prussian blue analogues (PBAs), with similar crystal structures to PB, can be obtained by replacing part or all of the irons by other transition-metal elements (e.g., $\mathrm{Co}, \mathrm{Ni}$ and $\mathrm{Mn}$ ) [14,15]. As electrode materials, the open framework of PB or PBAs could provide large interstitial sites for insertion/extraction of alkali metals ions [16]. Besides, the PBAs possess the advantages of relatively higher specific capacitance, environmental friendliness and low cost, which make it promising in the field of energy storage [17]. However, the poor electrical conductivity and serious agglomeration of PBAs' nanoparticles limit the 
effective utilization of their electrochemical performance [18]. To address this issue, two methods have been developed: (i) combining PBAs with conducting materials [19]; and (ii) increasing the reaction sites of PBAs by reducing the particle size with high specific surface area [20]. There have been a number of studies to synthesize PB/PBA and their composites for supercapacitors [21-24]. It is worth noting that mesopores are important for mass transport, which determines the accessing capability of electrolyte ions to the intrinsic micro-channels of PB/PBA [25]. However, the synthesis of mesoporous PB/PBAs has scarcely been reported.

In this work, we developed a facile and controllable sacrificial template route to prepare mesoporous cobalt hexacyanoferratenanocubes (meso-CoHCF). The as-prepared meso-CoHCF possesses a high specific surface area of $548.5 \mathrm{~m}^{2} \cdot \mathrm{g}^{-1}$ and a large amount of mesopores centered at $4.6 \mathrm{~nm}$. The meso-CoHCF electrodes exhibit a high specific capacitance of $285 \mathrm{~F} \cdot \mathrm{g}^{-1}$ at a scan rate of $2 \mathrm{mV} \cdot \mathrm{s}^{-1}$ in neutral $\mathrm{Na}_{2} \mathrm{SO}_{4}$ electrolyte, which is much higher than that of the controlled $\mathrm{CoHCF}$ nanoparticles (CoHCF, $215 \mathrm{~F} \cdot \mathrm{g}^{-1}$ ).

\section{Discussion and Results}

\subsection{Characterization of Meso-CoHCF}

Figure 1a-c exhibits the morphology of the meso-CoHCF sample. From the low magnification field-emission scanning electron microscopy (SEM) image (Figure 1a), the meso-CoHCF sample is composed of uniform nanocubes with sizes in the range of 300-500 nm. A closer observation from the high-resolution SEM image (Figure $1 b$ ) reveals the presence of mesopores on the exterior surface. The porous microstructure is verified by transmission electron microscopy (TEM) imaging, which shows the existence of numerous voids in the interior of the nanocubes. For comparison, CoHCF nanoparticles were synthesized by conventional chemical precipitation method. Figure $1 \mathrm{~d}-\mathrm{f}$ show the SEM and TEM images of the CoHCF nanoparticles. It is observed that the irregular CoHCF nanoparticles are of solid morphology.
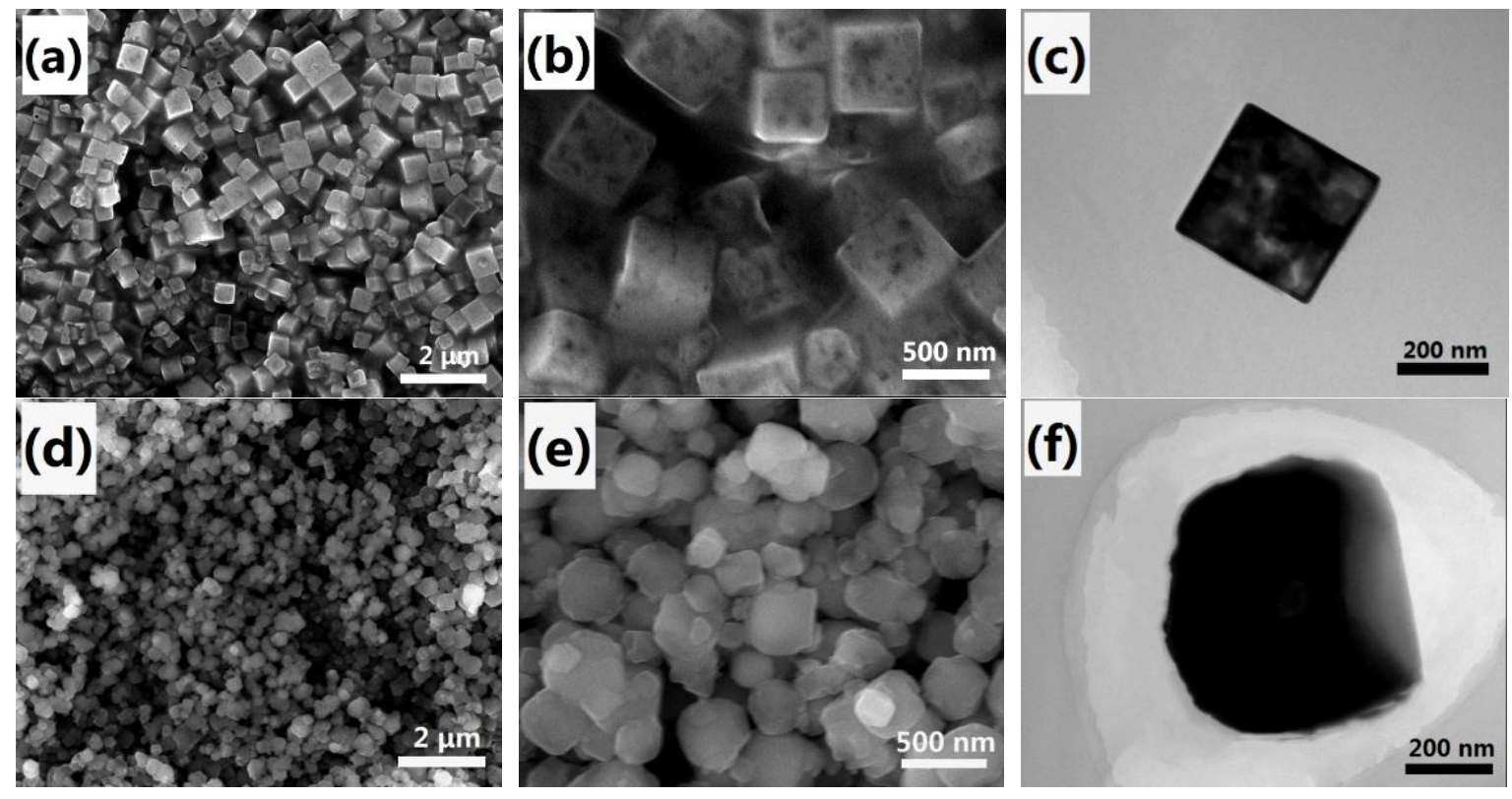

Figure 1. SEM and TEM images of meso-CoHCF nanocubes $(\mathbf{a}-\mathbf{c})$ and CoHCF nanoparticles (d-f).

The phase structure of the products is investigated by X-ray diffraction (XRD). As shown in Figure 2a, the meso-CoHCF and CoHCF samples show identical diffraction pattern, in which the diffraction peaks can be well indexed to the face-centered cubic phase of $\mathrm{Co}_{3}\left[\mathrm{Fe}(\mathrm{CN})_{6}\right]_{2} \cdot x \mathrm{H}_{2} \mathrm{O}$ [26] . No other diffraction peaks are noted, indicating a high purity of the products. To determine the 
chemical structure of CoHCF, Fourier-transform infrared (FTIR) spectra were collected. As shown in Figure 2b, the strong absorption band at $2104 \mathrm{~cm}^{-1}$ is characteristic of PB structure, which can be assigned to the stretching vibration of $\mathrm{Fe}-\mathrm{CN}-\mathrm{Co}$ bonds. The absorption peaks at 3407 and $1620 \mathrm{~cm}^{-1}$ can be attributed to the stretching and bending modes of the $\mathrm{H}-\mathrm{O}-\mathrm{H}$, respectively, indicating the existence of the interstitial water in the crystal lattice of the sample [27].
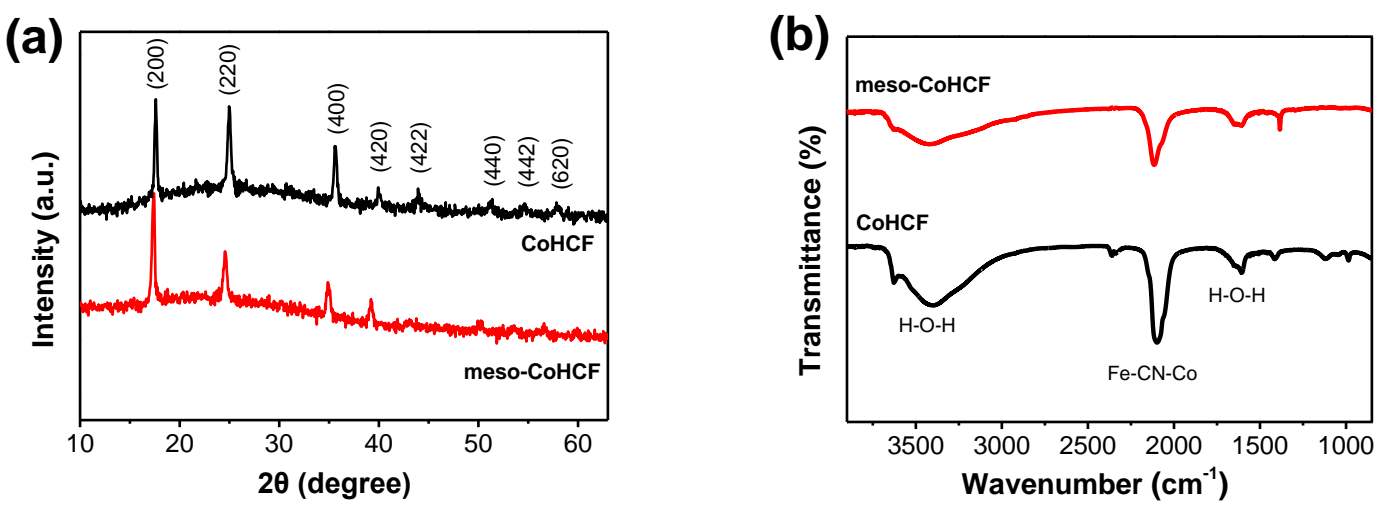

Figure 2. (a) XRD patterns and (b) FTIR spectraof meso-CoHCF and CoHCF.

The elemental components and their chemical states of the meso-CoHCF were examined by X-ray photoelectron spectroscopy (XPS) measurements. As shown in Figure 3a, the full scan spectrum shows the existence of $\mathrm{Co}, \mathrm{Fe}, \mathrm{O}, \mathrm{N}$ and $\mathrm{C}$ elements in the sample. Two pairs of subpeaks are present in the high-resolution spectra of Fe2p (Figure 3b). The binding energies at 723.5 and $710.0 \mathrm{eV}$ can be assigned to the $\mathrm{Fe}^{3+}$ in $\left[\mathrm{Fe}(\mathrm{CN})_{6}\right]^{3+}$, while the peaks at 721.1 and $708.2 \mathrm{eV}$ belong to the $\mathrm{Fe}^{2+}$ in $\left[\mathrm{Fe}(\mathrm{CN})_{6}\right]^{4+}[27,28]$. The spectrum of N1 s (Figure 3c) displays a distinct peak located at $397.9 \mathrm{eV}$, corresponding to the $\mathrm{C} \equiv \mathrm{N}$ in $\left[\mathrm{Fe}(\mathrm{CN})_{6}\right.$ ] groups [29]. The $\mathrm{C} 1 \mathrm{~s}$ spectrum (Figure $3 \mathrm{~d}$ ) can be fitted by three component curves centered at $288.3,285.6$ and $284.6 \mathrm{eV}$, representing $\mathrm{O}-\mathrm{C}=\mathrm{O}, \mathrm{C} \equiv \mathrm{N}$ and $\mathrm{C}-\mathrm{C}$ bonds, respectively.
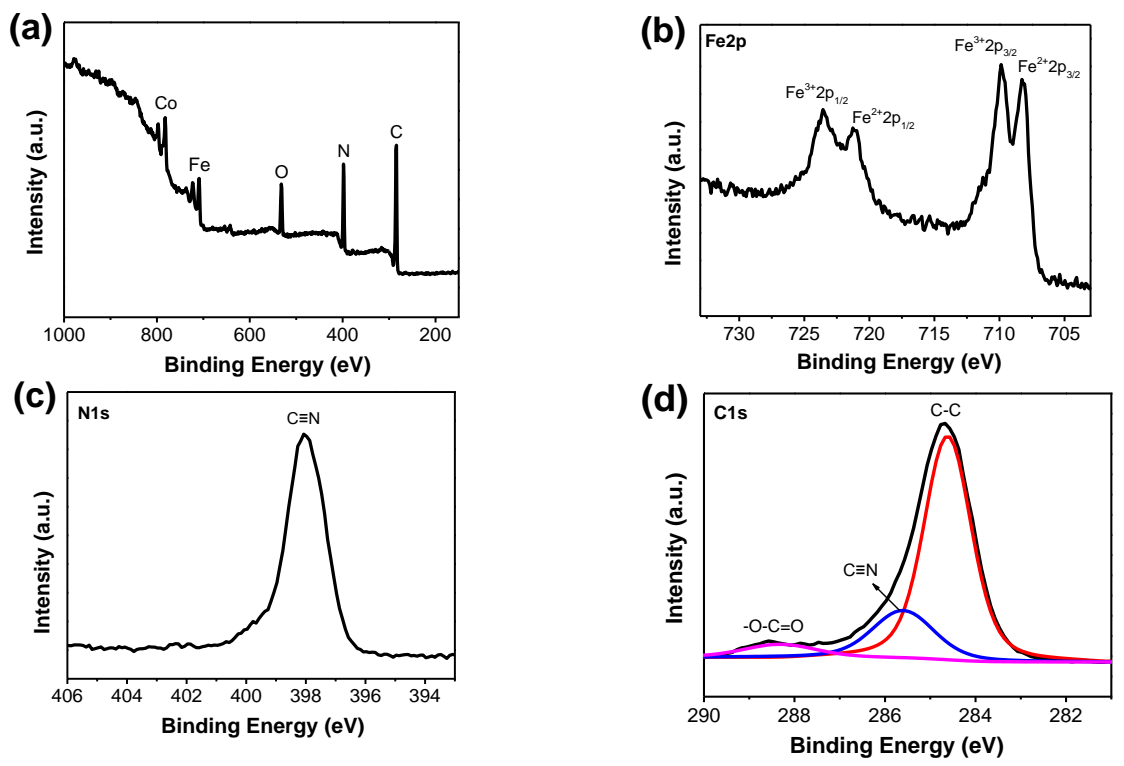

Figure 3. XPS spectra of meso-CoHCF: (a) full scan; (b) Fe2p; (c) N1s and (d) C1s.

The porous characteristics of the samples were investigated by $\mathrm{N}_{2}$ adsorption-desorption measurements. Figure $4 \mathrm{a}, \mathrm{b}$ exhibits the resulting isotherms of meso-CoHCF and CoHCF. The meso-CoHCF possesses a large hysteresis loop in the middle $\mathrm{P} / \mathrm{P}_{0}$ region, indicating the presence 
of uniform mesopores. The corresponding Barrett-Joyner-Halenda (BJH) pore-size distribution plots are displayed as inserts in Figure 4. It is noted that the meso-CoHCF sample has uniform mesopore size centered at $4.6 \mathrm{~nm}$. In sharp contrast, the controlled CoHCF sample shows irregular large pores in the range of 10-100 nm, which come from the agglomeration of the nanoparticles. More remarkably, the Brunauer-Emmett-Teller (BET) specific surface area of the meso-CoHCF is as large as $548.5 \mathrm{~m}^{2} \cdot \mathrm{g}^{-1}$, which is much higher than that of the CoHCF $\left(70.0 \mathrm{~m}^{2} \cdot \mathrm{g}^{-1}\right)$. The high surface area along with the uniform mesoporous structure of the meso-CoHCF provide more accessible electro-active sites for charge storage and allow for easy transport of electrolyte ions.
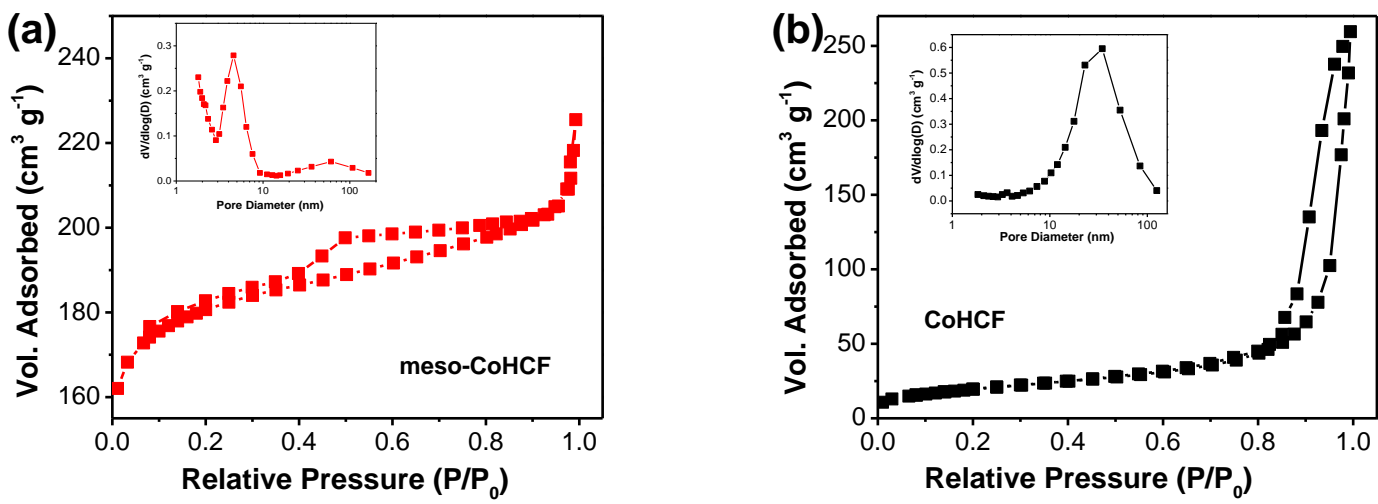

Figure 4. $\mathrm{N}_{2}$ adsorption/desorption isotherm and pore size distribution of (a) meso-CoHCF and (b) $\mathrm{CoHCF}$.

\subsection{Electrochemical Performance}

The electrochemical properties of the meso-CoHCF electrode were evaluated by cyclic voltammetry $(\mathrm{CV})$ and galvanostatic charge/discharge techniques in $0.5 \mathrm{M} \mathrm{Na}_{2} \mathrm{SO}_{4}$ aqueous electrolyte. Figure 5 shows the $\mathrm{CV}$ curves of the meso-CoHCF and CoHCF electrodes at various scan rates. Both electrodes exhibit typical pseudocapacitive behavior, which features a pair of redox peaks associated with transition between $\mathrm{Fe}^{2+}$ and $\mathrm{Fe}^{3+}$ in CoHCF [30]. The symmetric peak shape indicates good reaction reversibility. Compared to the $\mathrm{CoHCF}$ electrode (Figure $5 b$ ), the CV shape of the meso-CoHCF electrode is well maintained as the scan rate increases to $30 \mathrm{mV} \cdot \mathrm{s}^{-1}$, indicating better rate capability of the meso-CoHCF electrode with small polarization. The larger current density of the meso-CoHCF electrode at each scan rate manifests a higher specific capacitance. In addition, it is interesting to note that the high-specific-surface-area meso-CoHCF electrode exhibits an approximately rectangular CV shape in the high potential region of $0.8-1.0 \mathrm{~V}$, as shown in Figure $5 \mathrm{c}$, which is totally different from the $\mathrm{CoHCF}$ electrode, demonstrating that there are some electrochemical double layer (EDL) capacitance contributing to the overall capacitance. More importantly, the specific capacitance of the meso-CoHCF electrode is as high as $285 \mathrm{~F} \cdot \mathrm{g}^{-1}$ at $2 \mathrm{mV} \cdot \mathrm{s}^{-1}$, which is much higher than that of the controlled electrode ( $\left.215 \mathrm{~F} \cdot \mathrm{g}^{-1}\right)$. Moreover, the meso-CoHCF electrode exhibit better capacitance performance (e.g., $272 \mathrm{~F} \cdot \mathrm{g}^{-1}$ at $5 \mathrm{mV} \cdot \mathrm{s}^{-1}$ ) than the reported manganese hexacyanoferrat/manganese dioxide ( $\mathrm{MnHCF} / \mathrm{MnO}_{2}$ ) composites electrode (225.6 F.g $\mathrm{g}^{-1}$ at $5 \mathrm{mV} \cdot \mathrm{s}^{-1}$ ) [21], CoHCF nanoparticles electrode (250 F.g ${ }^{-1}$ at $\left.5 \mathrm{mV} \cdot \mathrm{s}^{-1}\right)$ [24], meso-NiHCF $\left(184 \mathrm{~F} \cdot \mathrm{g}^{-1}\right.$ at $\left.5 \mathrm{mV} \cdot \mathrm{s}^{-1}\right)$ and meso-CuHCF $\left(243 \mathrm{~F} \cdot \mathrm{g}^{-1}\right.$ at $\left.5 \mathrm{mV} \cdot \mathrm{s}^{-1}\right)$ [23].

Figure $6 \mathrm{a}, \mathrm{b}$ shows the galvanostatic charge/discharge curves of the meso-CoHCF and CoHCF electrodes at different current densities from 0.5 to $10 \mathrm{~A} \cdot \mathrm{g}^{-1}$. Both curves exhibit a long charge/discharge voltage plateau at $0.3-0.6 \mathrm{~V}$, which is consistent with the redox peaks in CV curves. The symmetric charge/discharge profiles indicate a high Coulombic efficiency. Figure $6 \mathrm{c}$ plots the specific capacitance of the meso-CoHCF and CoHCF electrodes at various current densities. The specific capacitance of both electrodes decreases with the increase of the current density due to the reduced diffusion time at a high current rate $[31,32]$. It is noted that the meso-CoHCF electrode 
can deliver a highspecific capacitance of $273 \mathrm{~F} \cdot \mathrm{g}^{-1}$ at $0.5 \mathrm{~A} \cdot \mathrm{g}^{-1}$, and sustains an excellent capacitance retention of $73.6 \%$ even at $10 \mathrm{~A} \cdot \mathrm{g}^{-1}$. However, the controlled $\mathrm{CoHCF}$ electrode can only deliver specific capacitance of 212 and $119 \mathrm{~F} \cdot \mathrm{g}^{-1}$ at 0.5 and $10 \mathrm{~A} \cdot \mathrm{g}^{-1}$, respectively. The higher specific capacitance along with the better rate capability of the meso-CoHCF electrode can be attributed to the unique porous structure: (i) the higher BET specific surface area provides more accessible electro-active sites for charge storage; and (ii) the uniform mesopores facilitate fast mass transport of electrolyte ions throughout the electrode for better reaction kinetics.
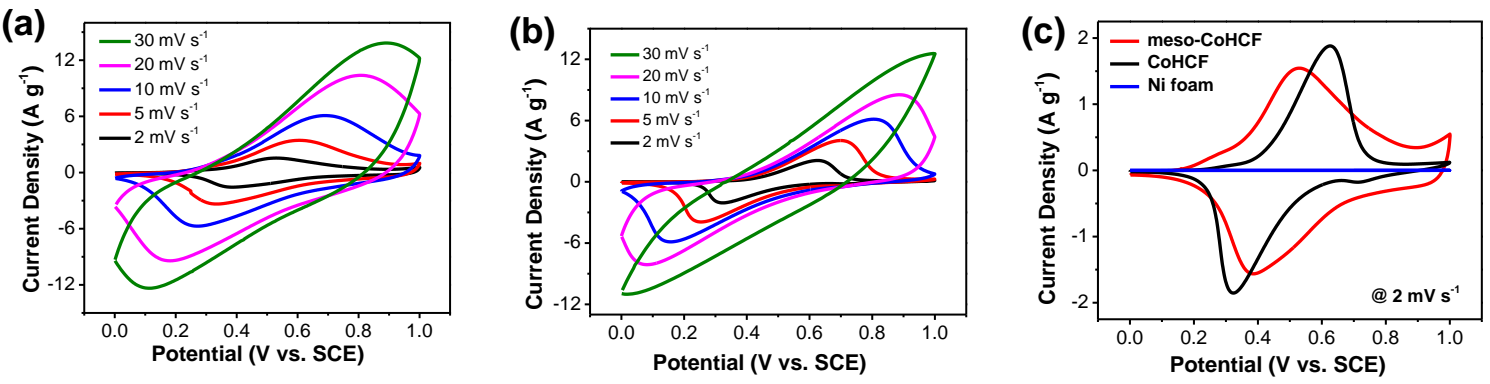

Figure 5. CV curves of (a) meso-CoHCF and (b) CoHCF electrodes and (c) their comparison at $2 \mathrm{mV} \cdot \mathrm{s}^{-1}$.

(a)
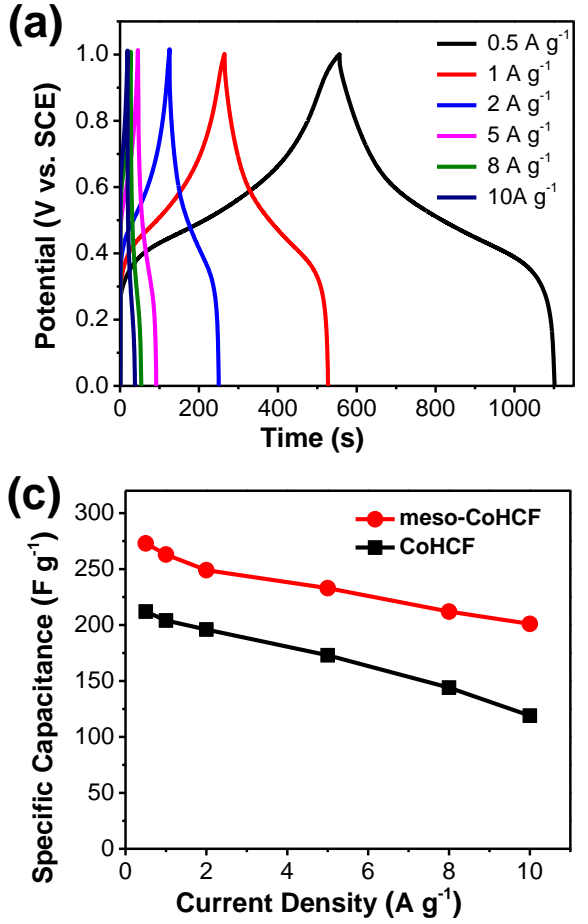
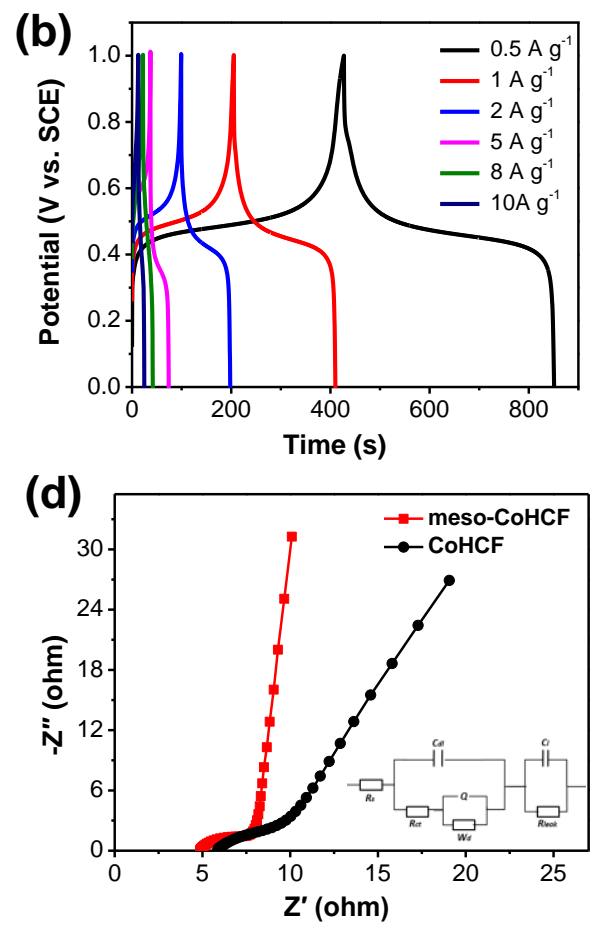

Figure 6. (a) Charge/discharge curves of meso-CoHCF electrode and (b) CoHCF electrode; and (c) their corresponding specific capacitance and (d) Nyquist plots.

To further understand the electrochemical behavior of the electrodes, electrochemical impedance spectrum (EIS) measurements were performed and the resulting Nyquist plots are shown in Figure 6d. The EIS data can be fitted using an equivalent circuit model (insert). It can be observed that the EIS curves are composed of a semicircle in the high frequency region and a sloped line in the low frequency region. The first $x$-intercept on the real axis $\left(Z^{\prime}\right)$ represents the bulk resistance of the electrode $\left(R_{s}\right)$, and the diameter of the semicircle corresponds to the charge-transfer resistance $\left(R_{c t}\right)$ [33]. Notably, both $R_{\mathrm{S}}(4.9 \Omega)$ and $\mathrm{R}_{\mathrm{ct}}(3.2 \Omega)$ of the meso-CoHCF electrode are much smaller than that of the CoHCF 
electrode (i.e., 6.1 and $4.3 \Omega$ ). The porous structure of the meso-CoHCF electrode provides more accessible sites for the charges accumulated at the surface, thereby resulting in a higher double layer capacitance $\left(\mathrm{C}_{\mathrm{dl}}\right)$ of around $85 \mu \mathrm{F}$ than that of the CoHCF electrode $(16 \mu \mathrm{F})$ [4]. In addition, the sloped line is associated with the electrolyte diffusion/transport into the porous electrode [32,33]. Clearly, the meso-CoHCF electrode possesses much more vertical shape, indicating lower diffusion resistance. It is anticipated that the lower internal and diffusion resistance of the meso-CoHCF electrode renders fast reaction kinetics for better power delivery.

Good cycling stability is an important criterion for supercapacitors in practical applications. Figure 7 shows the cycling performance of the meso-CoHCF and CoHCF electrodes at a large current density of $10 \mathrm{~A} \cdot \mathrm{g}^{-1}$. The meso-CoHCF electrode retains $92.9 \%$ of the initial capacitance after 3000 cycles, revealing long-term cycling stability. By contrast, the CoHCF electrode shows a serious capacitance degradation of $26.9 \%$ over the 3000 -cycle test. The better cycling stability of the meso-CoHCF electrode may benefit from the voidspace in the interior of the nanocubes, which can accommodate the possible volume expansion and contraction during the long-term operation. To confirm it, the morphology of the meso-CoHCF electrode after cycling test is characterized. As shown in the inset of Figure 7, the nanocubes are well maintained after cycling, indicating the robust structure of the meso-CoHCF.

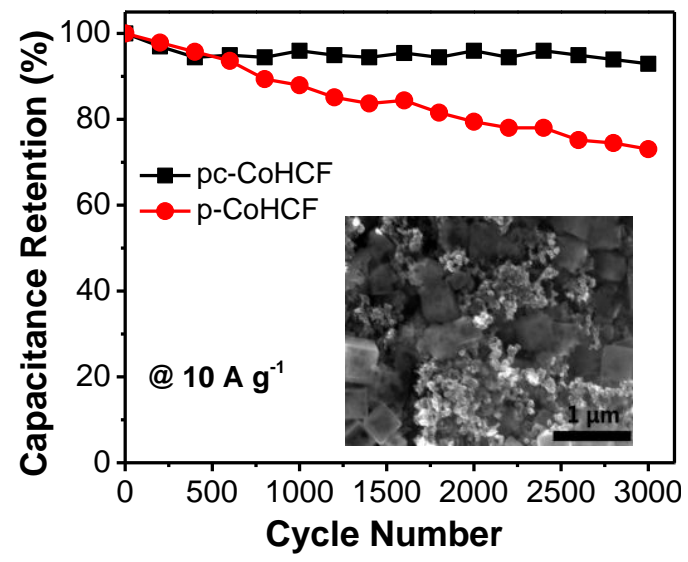

Figure 7. Cycle stability of meso-CoHCF and CoHCF electrodes. Inset shows the morphology of the meso-CoHCF electrode after cycling test.

\section{Materials and Methods}

Materials Synthesis: All chemical reagents were analytical grade and purchased from Sinopharm Chemical Reagent Co., Ltd. (Shanghai, China). In a typical synthesis procedure of the meso-CoHCF, $0.4 \mathrm{~g}$ of polyvinylpyrrolidone (PVP) and $100 \mathrm{mg}$ of $\mathrm{MnSO}_{4} \mathrm{H}_{2} \mathrm{O}$ were dissolved in $10 \mathrm{~mL}$ ethanol and $10 \mathrm{~mL} \mathrm{H}_{2} \mathrm{O}$, respectively, under stirring for $30 \mathrm{~min}$ to form a homogeneous solution. Next, $10 \mathrm{~mL}$ of $0.03 \mathrm{M}$ potassium ferricyanide $\left(\mathrm{K}_{3} \mathrm{Fe}(\mathrm{CN})_{6}\right)$ was added in $3 \mathrm{~min}$ and kept under stirring overnight to form MnHCF template. Then, $10 \mathrm{~mL}$ of $0.045 \mathrm{M} \mathrm{Co}\left(\mathrm{NO}_{3}\right)_{2} 6 \mathrm{H}_{2} \mathrm{O}$ was mixed with the above suspension and let stand for $5 \mathrm{~h}$ at $50^{\circ} \mathrm{C}$. Finally, the meso-CoHCF products were obtained after filtration (the pore diameter of filter paper was $\sim 0.45 \mu \mathrm{m}$ ) and washing with deionized water and finally drying at $80{ }^{\circ} \mathrm{C}$ for $12 \mathrm{~h}$. For comparison, CoHCF nanoparticles were prepared by directly mixing $20 \mathrm{~mL}$ of $15 \mathrm{mM} \mathrm{Co}\left(\mathrm{NO}_{3}\right)_{2}$ with $20 \mathrm{~mL} 10 \mathrm{mM} \mathrm{K}_{3} \mathrm{Fe}(\mathrm{CN})_{6}$ under stirring for $3 \mathrm{~h}$. The precipitates were filtered, rinsed and dried using a similar process.

Materials Characterization: The crystalline structures of the as-prepared products were characterized by X-ray powder diffraction (XRD, X'Pert Pro MPD, Philips, Almelo, The Netherlands). The Fourier-transform infrared (FT-IR, Nicolet iS50, Thermo Fisher Scientific, Waltham, MA, USA) spectra were collected in the region from 800 to $4000 \mathrm{~cm}^{-1}$ to detect the chemical components of the samples. X-ray photoelectron spectroscopy (XPS, ESCALAB 250Xi, Thermo Scientific, Waltham, 
MA, USA) measurements were applied to investigate the elemental composition and surface chemistry. The morphology of the samples was observed with field emission scanning electron microscopy (FE-SEM, FEI NanoSEM 450, FEI, Portland, OR, USA) and transmission electron microscopy (TEM, FEI Tecnai F30G2, FEI, Portland, OR, USA). The porous characteristics of the products was measured by $\mathrm{N}_{2}$ adsorption-desorption isotherms (ASAP 2020, Mike, Norcross, GA, USA). The specific surface area was calculated using the BET method while the pore size distribution was determined by BJH model.

Electrochemical Measurements:The electrochemical tests of meso-CoHCF electrodes were performed on an electrochemical workstation (Solartron $1260+1287$, Bognor Regis, West Sussex, UK) with a three-electrode configuration system. For the preparation of the working electrode, the active materials, carbon black and polytetrafluoroethylene (PTFE) were mixed with a mass ratio of 7:2:1 and stirred for $2 \mathrm{~h}$. The working electrode was yielded after uniformly painting the above slurry on the nickel foam $(1 \times 2 \mathrm{~cm})$ and drying at $90{ }^{\circ} \mathrm{C}$ for $12 \mathrm{~h}$ in an oven. Platinum foil and saturated calomel electrode (SCE) served as counter electrode and reference electrode, respectively, and a $0.5 \mathrm{M}$ $\mathrm{Na}_{2} \mathrm{SO}_{4}$ aqueous solution was employed as electrolyte. The mass loading of active materials on the working electrode was around $2.0 \mathrm{mg} \cdot \mathrm{cm}^{-2}$. The cyclic voltammetry $(\mathrm{CV})$ and galvanostatic charge-discharge techniques were employed within a potential window ranging from 0.0 to $1.0 \mathrm{~V}$. to evaluate the electrochemical performance of the working electrodes [34]. The electrochemical impedance spectroscopy (EIS) measurements were conducted in the frequency range of $10 \mathrm{kHz}$ to $0.01 \mathrm{~Hz}$.

\section{Conclusions}

A facile chemical-processing method has been developed in our work to prepare the mesoporous CoHCF nanocubes for supercapcitors. The meso-CoHCF with size between 300 and $500 \mathrm{~nm}$ show a high specific surface area of $548.5 \mathrm{~m}^{2} \cdot \mathrm{g}^{-1}$ and sufficient meso-channels, which not only offers abundant electro-active sites but also facilitates the mass transport of electrolyte. The meso-CoHCF electrodes exhibit a high specific capacitance of $285 \mathrm{~F} \cdot \mathrm{g}^{-1}$ at a scan rate of $2 \mathrm{mV} \cdot \mathrm{s}^{-1}$ and excellent rate capability in $\mathrm{Na}_{2} \mathrm{SO}_{4}$ aqueous electrolyte. In addition, the capacitance retention is as high as $92.9 \%$ after 3000 cycles at a large current density of $10 \mathrm{~A} \cdot \mathrm{g}^{-1}$. The high specific capacitance, good rate capability and long cycle life makethe meso-CoHCFpromising as supercapacitor electrode materials for practical applications.

Acknowledgments: The authors acknowledge the financial support for this work from the National Natural Science Foundation of China $(51772249,51402236,51472204)$, the Research Fund of the State Key Laboratory of Solidification Processing (NWPU), China (Grant No.: 123-QZ-2015), the Key Laboratory of New Ceramic and Fine Processingand State Key Laboratory of Control and Simulation of Power System and Generation Equipment (Tsinghua University, KF201607, SKLD17KM02), and the Fundamental Research Funds for the Central Universities.

Author Contributions: Jian-Gan Wang and Zhiyong Zhang conceived, designed and performed the experiments; Jian-Gan Wang, Zhiyong Zhang and Bingqing Wei analyzed the results and co-wrote this paper.

Conflicts of Interest: The authors declare no conflict of interest. The founding sponsors had no role in the design of the study; in the collection, analyses, or interpretation of data; in the writing of the manuscript, and in the decision to publish the results.

\section{References}

1. Wang, J.; Kang, F.; Wei, B. Engineering of $\mathrm{MnO}_{2}$-based nanocomposites for high-performance supercapacitors. Prog. Mater. Sci. 2015, 74, 51-124. [CrossRef]

2. Li, H.; Yu, M.; Wang, F.; Liu, P.; Liang, Y.; Xiao, J.; Wang, C.; Tong, Y.; Yang, G. Amorphous nickel hydroxide nanospheres with ultrahigh capacitance and energy density as electrochemical pseudocapacitor materials. Nat. Commun. 2013, 4, 1894. [CrossRef] [PubMed]

3. Li, B.; Dai, F.; Xiao, Q.; Yang, L.; Shen, J.; Zhang, C.; Cai, M. Nitrogen-doped activated carbon for a high energy hybrid supercapacitor. Energ. Environ. Sci. 2016, 9, 102-106. [CrossRef]

4. Masarapu, C.; Zeng, H.; Wei, B. Effect of temperature on the capacitance of carbon nanotube supercapacitors. ACS Nano 2009, 3, 2199-2206. [CrossRef] [PubMed] 
5. Wang, J.-G.; Zhang, C.; Jin, D.; Xie, K.; Wei, B. Synthesis of ultralong MnO/C coaxial nanowires as freestanding anodes for high-performance lithium ion batteries. J. Mater. Chem. A 2015, 3, 13699-13705. [CrossRef]

6. Peng, Z.; Lin, J.; Ye, R.; Samuel, E.; Tour, J. Flexible and stackable laser-induced graphene supercapacitors. ACS Appl. Mater. Interfaces 2015, 7, 3414-3419. [CrossRef] [PubMed]

7. Wang, J.-G.; Jin, D.; Zhou, R.; Shen, C.; Xie, K.; Wei, B. One-step synthesis of $\mathrm{NiCo}_{2} \mathrm{~S}_{4}$ ultrathin nanosheets on conductive substrates as advanced electrodes for high-efficient energy storage. J. Power Sources 2016, 306, 100-106. [CrossRef]

8. Chen, H.; Hu, L.; Chen, M.; Yan, Y.; Wu, L. Nickel-cobalt layered double hydroxide nanosheets for high-performance supercapacitor electrode materials. Adv. Funct. Mater. 2014, 24, 934-942. [CrossRef]

9. Yue, Y.; Binder, A.; Guo, B.; Zhang, Z.; Qiao, Z.; Tian, C.; Dai, S. Mesoporous prussian blue analogues: Template-free synthesis and sodium-ion battery applications. Angew. Chem. Int. Edit. 2014, 53, 3134-3137. [CrossRef] [PubMed]

10. Wang, J.-G.; Jin, D.; Liu, H.; Zhang, C.; Zhou, R.; Shen, C.; Xie, K.; Wei, B. All-manganese-based Li-ion batteries with high rate capability and ultralong cycle life. Nano Energy 2016, 22, 524-532. [CrossRef]

11. Liu, S.; Pan, G.; Li, G.; Gao, X. Copper hexacyanoferrate nanoparticles as cathode material for aqueous Al-ion batteries. J. Mater. Chem. A 2015, 3, 959-962. [CrossRef]

12. Su, D.; McDonagh, A.; Qiao, S.; Wang, G. High-capacity aqueous potassium-ion batteries for large-scale energy storage. Adv. Mater. 2017, 29, 1604007. [CrossRef] [PubMed]

13. Kong, B.; Selomulya, C.; Zheng, G.; Zhao, D. New faces of porous prussian blue: Interfacial assembly of integrated hetero-structures for sensing applications. Chem. Soc. Rev. 2015, 44, 7997-8018. [CrossRef] [PubMed]

14. Shiba, F.; Fujishiro, R.; Kojima, T.; Okawa, Y. Preparation of monodisperse cobalt(II) hexacyanoferrate(III) nanoparticles using cobalt ions released from a citrate complex. J. Phys. Chem. C 2012, 116, 3394-3399. [CrossRef]

15. Subramani, K.; Jeyakumar, D.; Sathish, M. Manganese hexacyanoferrate derived $\mathrm{Mn}_{3} \mathrm{O}_{4}$ nanocubes-reduced graphene oxide nanocomposites and their charge storage characteristics in supercapacitors. Phys. Chem. Chem. Phys. 2014, 16, 4952-4961. [CrossRef] [PubMed]

16. Mizuno, Y.; Okubo, M.; Hosono, E.; Kudo, T.; Oh-ishi, K.; Okazawa, A.; Kojima, N.; Kurono, R.; Nishimura, S.; Yamada, A. Electrochemical $\mathrm{Mg}^{2+}$ intercalation into a bimetallic CuFe prussian blue analog in aqueous electrolytes. J. Mater. Chem. A 2013, 1, 13055-13059. [CrossRef]

17. You, Y.; Wu, X.; Yin, Y.; Guo, Y. High-quality prussian blue crystals as superior cathode materials for room-temperature sodium-ion batteries. Energy Rnviron. Sci. 2014, 7, 1643-1647. [CrossRef]

18. Zou, Y.; Wang, Q.; Xiang, C.; She, Z.; Chu, H.; Qiu, S.; Xu, F.; Liu, S.; Tang, C.; Sun, L. One-pot synthesis of ternary polypyrrole-prussian-blue-graphene-oxide hybrid composite as electrode material for high-performance supercapacitors. Electrochim. Acta 2016, 188, 126-134. [CrossRef]

19. Wang, J.; Zhang, Z.; Liu, X.; Wei, B. Facile synthesis of cobalt hexacyanoferrate/graphene nanocomposites for high-performance supercapacitor. Electrochim. Acta 2017, 235, 114-121. [CrossRef]

20. Moo Lee, K.; Tanaka, H.; Ho Kim, K.; Kawamura, M.; Abe, Y.; Kawamoto, T. Improvement of redox reactions by miniaturizing nanoparticles of zinc prussian blue analog. Appl.Phys.Lett. 2013, 102, 141901-141903. [CrossRef]

21. Wang, Y.; Zhong, H.; Hu, L.; Yan, N.; Hu, H.; Chen, Q. Manganese hexacyanoferrate $/ \mathrm{MnO}_{2}$ composite nanostructures as a cathode material for supercapacitors. J. Mater. Chem. A 2013, 1, 2621-2630. [CrossRef]

22. Wang, Y.; Chen, Q. Dual-Layer-Structured nickel hexacyanoferrate $/ \mathrm{MnO}_{2}$ composite as a high-energy supercapacitive material based on the complementarity and interlayer concentration enhancement effect. ACS Appl. Mater. Interfaces 2014, 6, 6196-6201. [CrossRef] [PubMed]

23. Yue, Y.; Zhang, Z.; Binder, A. Hierarchically superstructured prussian blue analogues: Spontaneous assembly synthesis and applications as pseudocapacitive materials. ChemSusChem 2015, 8, 177-183. [CrossRef] [PubMed]

24. Zhao, F.; Wang, Y.; Xu, X.; Liu, Y.; Song, R.; Lu, G.; Li, Y. Cobalt hexacyanoferrate nanoparticles as a high-rate and ultra-stable supercapacitor electrode material. ACS Appl. Mater. Interfaces. 2014, 6, 11007-11012. [CrossRef] [PubMed] 
25. Yue, Y.; Fulvio, P.F.; Dai, S. Hierarchical Metal-Organic Framework Hybrids: Perturbation-Assisted Nanofusion Synthesis. Acc. Chem. Res. 2015, 48, 3044-3052. [CrossRef] [PubMed]

26. Lu, K.; Song, B.; Gao, X.; Dai, H.; Zhang, J.; Ma, H. High-energy cobalt hexacyanoferrate and carbon micro-spheres aqueous sodium-ion capacitors. J. Power Sources 2016, 303, 347-353. [CrossRef]

27. Wang, J.-G.; Zhang, Z.; Zhang, X.; Yin, X.; Li, X.; Liu, X.; Kang, F.; Wei, B. Cation exchange formation of prussian blue analogue submicroboxes for high-performance Na-ion hybrid supercapacitors. Nano Energy 2017, 39, 647-653. [CrossRef]

28. Wu, X.; Luo, Y.; Sun, M.; Qian, J.; Cao, Y.; Ai, X.; Yang, H. Low-defect prussian blue nanocubes as high capacity and long life cathodes for aqueous Na-ion batteries. Nano Energy 2015, 13, 117-123. [CrossRef]

29. Luo, X.; Pan, J.; Pan, K.; Yu, Y.; Zhong, A.; Wei, S.; Li, J.; Shi, J.; Li, X. An electrochemical sensor for hydrazine and nitrite based on graphene-cobalt hexacyanoferrate nanocomposite: Toward environment and food detection. J. Electroanal. Chem. 2015, 745, 80-87. [CrossRef]

30. Luo, M.; Dou, Y.; Kang, H.; Ma, Y.; Ding, X.; Liang, B.; Ma, B.; Li, L. A novel interlocked prussian blue/reduced graphene oxide nanocomposites as high-performance supercapacitor electrodes. J. Solid State Electrochem. 2015, 19, 1621-1631. [CrossRef]

31. Wang, J.; Yang, Y.; Huang, Z.; Kang, F. Coaxial carbon nanofibers $/ \mathrm{MnO}_{2}$ nanocomposites as freestanding electrodes for high-performance electrochemical capacitors. Electrochim. Acta 2011, 56, 9240-9247. [CrossRef]

32. Wang, J.; Yang, Y.; Huang, Z. A high-performance asymmetric supercapacitor based on carbon and carbon- $\mathrm{MnO}_{2}$ nanofiber electrodes. Carbon 2013, 61, 190-199. [CrossRef]

33. Wang, J.; Jin, D.; Zhou, R.; Li, X.; Liu, X.; Shen, C.; Xie, K.; Li, B.; Kang, F.; Wei, B. Highly flexible graphene $/ \mathrm{Mn}_{3} \mathrm{O}_{4}$ nanocomposite membrane as advanced anodes for Li-ion batteries. ACS Nano 2016, 10, 6227-6234. [CrossRef] [PubMed]

34. Younis, A.; Chu, D.; Li, S. Ethanol-directed morphological evolution of hierarchical $\mathrm{CeO}_{x}$ architectures as advanced electrochemical capacitors. J. Mater. Chem. A 2015, 3, 13970-13977. [CrossRef]

(C) 2017 by the authors. Licensee MDPI, Basel, Switzerland. This article is an open access article distributed under the terms and conditions of the Creative Commons Attribution (CC BY) license (http:/ / creativecommons.org/licenses/by/4.0/). 